\title{
Are Creative Cities Good Places for Creative People? Notes on the Social Conditions for Cultural Production in Contemporary Economy
}

\author{
DOI: 10.12776/QIP.V21I1.777
}

\begin{abstract}
João Romão
Received: 9 September 2016 Accepted: 17 January 2017 Published: 30 April 2017
\end{abstract}

\begin{abstract}
Purpose: This paper discusses the social conditions for cultural production in contemporary cities, in the context of a globalized economy, with rising importance of the integration of cognitive, symbolic and emotional elements into tradable products and services. Although the agglomeration dynamics of creative activities in urban contexts and the social or spatial inequalities related to processes of urban reorganization in Post-Fordist societies have been analysed in the last years, the interrelations between these aspects still lack adequate investigation and empirical analysis.

Methodology/Approach: By synthetizing diverse theoretical contributions related to different levels and interactions arising from creative activities, their transformations into tradable products (commodification) and some of their spatial implications in the urban context (agglomeration, externalities, identity, place branding and gentrification), the article emphasizes the different benefits obtained by the agents involved in this process, potentially contributing for increasing social conflicts and to a process of cultural homogenization with negative implications on the uniqueness and authenticity of places.
\end{abstract}

Findings: Benefits arising from the externalities generated by the agglomeration of cultural production and creative activities can be framed within the "Common Pool of Resources" approach, suggesting that a more balanced share of the benefits can be obtained by means of participatory processes for city planning and development.

Research Limitation/implication: The paper is based on a conceptual approach and further empirical research can be useful in order to test the formulations proposed. 
Originality/Value of paper: This analysis leads to the identification of different questions for further research, by combining quantitative analysis for the measurement of cultural and creative externalities and modelling processes for the distribution of benefits arising from cultural production, with qualitative analysis related to participatory processes of urban planning and monitoring.

Category: Research paper

Keywords: culture; creative economy; externalities; common pool of resources

\section{INTRODUCTION: CULTURE, ECONOMY AND THE CITY}

An increasing integration of cultural and symbolic values into tradable goods and services is a major characteristic of contemporary economies, with a significant expansion of the culturally oriented economic sectors. For the purposes of this study, focused on the social conditions for cultural production in contemporary cities, the formulation proposed by Scott (2007) to classify the contemporary economy - cognitive capitalism - is particularly useful, once it emphasizes the social contradictions and conflicts arising from a double process of commodification of culture: culture is growingly produced under a commodified and market oriented form, while commodity production (goods and services) increasingly integrates aesthetic and semiotic meanings.

For this author, this process of intensification of cerebral and affective labour in the modern economy is one of the central characteristics of the current stage of capitalism development, oriented to processes of monopolistic competition (due to the unique characteristics of products with embedded symbolic values), where cultural products and technology intensive manufacturing and services are the leading sectors, digital technologies constitute its technological foundations and labour relations tend to be more flexible, unstable, deregulated and precarious, which constitute a critical aspect for some contemporary social conflicts in urban context. Additionally, due to the attractiveness arising from agglomeration effects, the economy of contemporary cities also includes large numbers of workers with low-wages and low-skills, often arriving from less developed countries.

The analysis of cultural production requires a prior definition of culture, a broad concept often used with different meanings in different contexts. The definition proposed by UNESCO (2009) is adopted in this work: "a set of distinctive spiritual, material, intellectual and emotional features of society or a social group, that encompasses, not only art and literature, but lifestyles, ways of living together, value systems, traditions and beliefs". This involves a broad set of economic activities (related to the production of goods and services) and social involvement (participation in cultural initiatives). The concept of Culture Cycle model is also considered, emphasizing the social dynamics of cultural production, referring to the "practices, activities and necessary resources required to transform ideas into cultural goods and services and to reach consumers, 
participants or users", involving activities related to creation, production, dissemination, exhibition-reception-transmission and consumption-participation. This also includes the related domains of recreation and leisure ("partially cultural" activities) and the transversal domains of education and training, archiving and preserving or intangible cultural heritage.

These collective processes of transformation of ideas into cultural goods and services (symbolic value creation) can be observed by looking into the three layers proposed by Cohendet, Grandadam and Simon (2010): the "underground", involving artists and creators; the "upperground", formed by firms and public institutions; and the "middleground", the places and spaces where "underground" and "upperground" come together. Places are often public and not market-driven sites, activating relations between people and constituting physical platforms for building a common identity. Spaces are defined as cognitive platforms of knowledge, both local and global, where ideas can flow between communities. Thus, the "middleground" is the level where cultural and creative externalities are produced and accumulated.

The analysis of the dynamic relations between these layers of the process of cultural production clearly helps to understand the social conditions and conflicts arising from the creative activities in contemporary economies, through the creation, dispute and appropriation of externalities and monopoly rents generated by the distinctive characteristics of creative outputs. Some implications of these dynamic and conflictual processes on the urban structures will be analysed in the following sections. Although the agglomeration dynamics of creative activities in urban contexts (e.g., Florida, 2002; Van Geenhuizen and Nijkamp, 2012) and the social and spatial inequalities related to processes of urban reorganization (e.g., Doucet, 2014, in his introduction to a special issue focused on the analysis of different contemporary processes of urban gentrification) in Post-Fordist societies have been broadly analysed in the last years, the interrelations between these aspects still lack adequate investigation and empirical analysis.

This analysis offers a contribution to overcome this research gap, by identifying different questions for further research, combining quantitative methods for the measurement of cultural and creative externalities and modelling processes for the distribution of benefits arising from cultural production, with qualitative analysis related to participatory processes of urban planning and monitoring. The concepts and relationships under analysis are represented in Fig. 1: cultural production and externalities contributing for the agglomeration of creative activities are framed within the concept of "Common Pool Resources", while processes of appropriation of benefits through market dynamics are essentially commercially driven within the private realm, potentially generating social and spatial inequalities and implying public policies in order to preserve the characteristics of inclusive urban communities, along with their identity and creativity. 


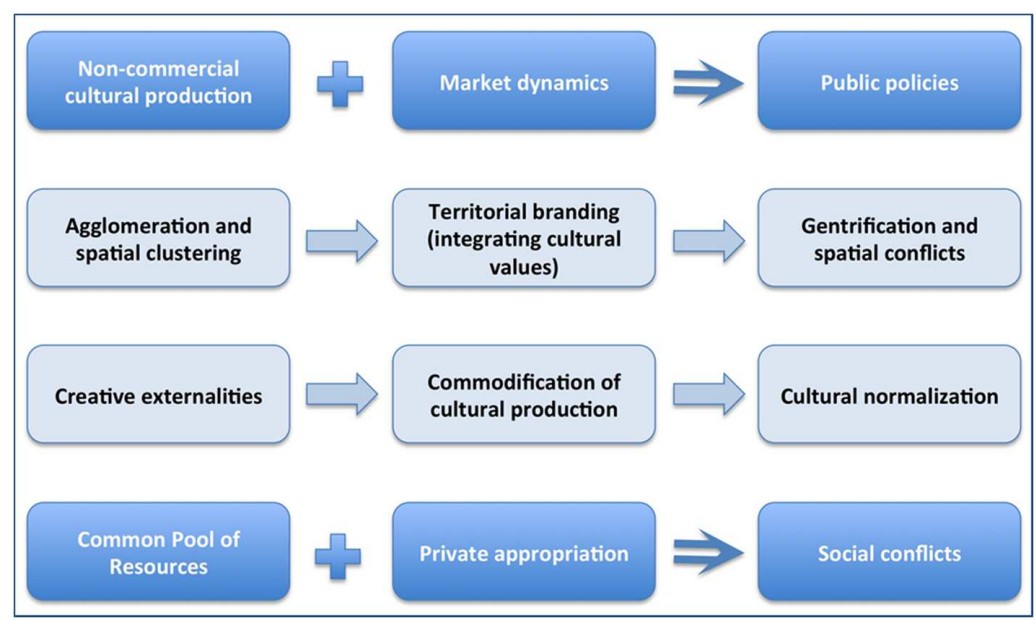

Figure 1 - Conceptual framework

\section{METHODOLOGY: A CONCEPTUAL FRAMEWORK FOR THE ANALYSIS OF CULTURAL PRODUCTION IN CONTEMPORARY CITIES}

\subsection{Creative externalities and community identities}

Contemporary cities are places where scale and variety come together, as a result of agglomeration effects, by attracting creative individuals and companies in search of externalities and efficiency benefits related to proximity and colocation. This process of spatial clustering of cultural industries is followed by creative individuals, migrating from peripheral to core cultural centres (e.g., Scott, 2008). In a globalized world, increasing competition for the attractiveness of skilled labour, efficient companies and investment flows also reinforces the role of governance and public institutions, aiming at the achievement of new forms of competitive advantage arising from the production and dissemination of knowledge and creativity.

In this sense, culture and creativity potentially create and/or reinforce the uniqueness and authenticity of urban centres, often being used for value creation through branding strategies for city or product commercial promotion (Okano and Samson, 2010). Even if the characteristics and qualities of a given product are normally specific to each firm, they are also the result of the evolution of a local economy, with its particular traditions and reputation. One example of this process of linkage between products and places is the "Place in Product" marketing approach, by relating creative goods and services to places where its production is notorious (Currid-Halkett and Scott, 2013). This process of commodification of culture and creativity often leads to processes of gentrification in urban areas, as a result of the concentration of creative activities, 
the creation or reinforcement of a unique and distinctive image of the place, the consequent competition for location and the related inflationary processes.

These processes of gentrification include transformations of urban space related to cognitive-cultural economic development, social transformation, functional changes and re-imaging through new symbologies (Scott, 2016). The same author (Scott, 2007) refers that this type of transformation in the urban space occurred in different contemporary cities, corresponding to the migration of former industrial workers to peripheral areas of the city, while the centre is occupied by new commercial or residential buildings, normally with an high status and high costs, benefiting from the creative agglomeration effects of the area and enhancements on the quality of infrastructures and urban amenities. In that sense, the presence of creative communities in a degraded urban area can be seen as a first sign of a gentrification process (Harvey, 2012).

A concrete analysis of one of these processes is offered by Avdikos (2015) for the neighbourhood of Kerameikos-Metaxourgeio, in the centre of the Greek city of Athens, in the beginning of the XXI century. By occupying unused former industrial building and warehouses, creative newcomers (the "underground") developed a particular and intense atmosphere that was followed by the "middleground" - the creation of places and spaces for cultural interaction, generating local creative externalities - and leading to the establishment of creative enterprises ("upperground"), mostly constituted by self-employed or very small firms, in a first stage. These dynamics generated a continuous flow of events and projects, quickly contributing for the creation of an identity related to the uniqueness of the creative environment. As a result, KerameikosMetaxourgeio achieved a status of notoriety, attracting private real estate investments and public interventions in the public spaces. During the period of economic crisis of 2007-2009, rents in the area have kept the pre-crisis levels or increased by 10-20\%, while an average fall of 30-50\% was observed in other areas of the centre of Athens. By then, the creative individuals and communities that had been at the beginning of the redevelopment process could not afford to live in that area.

In fact, as mentioned by Harvey (2012), the extraction of land and property rents is the most important means for the appropriation of urban areas: although the land rent is the result of a collective action performed at community level, eventually reinforced by public investments in infrastructures and amenities, the appropriation of the rent benefits is normally private, benefiting real estate companies and investors in the housing market. Keeping in mind the three levels of cultural production proposed and applied by Cohendet, Grandadam and Simon (2011) in different urban contexts, the "underground" ignites the creation of a creative atmosphere in an urban area, acting as a local repository of creative externalities within the "middleground". The creation of a local symbolic capital related to authenticity and uniqueness of the place generates monopoly rents, which are unequally appropriated by the "underground" and the "upperground" through their interaction within the "middleground". This is, in fact, a part of the 
"appropriation problem" related to the Common Pool Resources, to be discussed in the Fourth Section of this paper.

This inequality in the appropriation of benefits between the "underground" and the "upperground" relies on their different positions within the production process and control of the means of production: the "underground" is mostly constituted by independent individuals, generally with precarious or informal labour relations, being paid according to the projects they get involved, even if their work is often exploratory and not easily tradable in the markets; on the other hand, the "upperground" includes private firms and public institutions with financial resources and/or political power to influence and to decide about the structure and organization of urban areas. This dynamical process or urban transformation - arising from the development and agglomeration of creative activities and the resulting externalities - reveals how the power and practices of real estate entrepreneurs tend to capture the benefits generated by the individuals whose common effort helped to develop a creative neighbourhood.

As Harvey (2012) points out, "the better the common qualities a social group creates, the more likely it is to be raided and appropriated by private profit maximizing interests". This calls for new forms of coordination between cultural and economic dynamics, market regulation, public investments and urban planning, in order to benefit society as a whole and also to preserve the creative and identitarian characteristics of the neighbourhoods. Thus, the research gap and lack of empirical studies regarding these interrelations constitute an obstacle for the implementation of informed public policies.

\subsection{Spatial inequalities and social conflicts}

This social conflict arising from creative production - and its spatial implications - in contemporary cities can also be seen as a process of homogenization of culture, in which the symbolic capital of an area (related to its authenticity and uniqueness) generated by the creative externalities and spillovers created by cultural producers and creative agents ("the undergound") is tendentially destroyed (through a process of normalization) by market or institutional forces and branding strategies (the "upperground"), implying an unequal distribution of benefits related both to the extraction of symbolic values and to the processes for its future creation.

Thus, cultural production can enhance the social conflicts emerging in contemporary cities, where it is also visible a tendency for higher inequalities, spatially expressed by the differences in living conditions in central, well equipped, residential areas (sometimes functioning as "close" spaces, with restricted access) and large suburban, peripheral areas, with low levels of infrastructures, where low skilled workers attracted by the job opportunities in the cities tend to concentrate. Davis (2006) proposes a detailed analysis of the global expansion of these suburban and unqualified areas of social exclusion, as a 
characteristic of the contemporary processes of urban development, which promote an unprecedented human settlement in urban centres.

The unequal social conditions faced by the citizens living in central or peripheral urban areas are related to what Scott (2007) defines as multiple negative externalities, related to high mobility costs, lack of infrastructures, difficult access to a large number of public and private services, etc. In addition, many of these suburban residents are migrants, often with language barriers to adaptation, low professional and social skills, poor integration in local networks and, eventually, lack of a legal residence status. Thus, the social inequalities expressed in the spatial inequalities in the occupation of the city also raise problems of democracy, through the limitations that are often imposed to an effective citizenship of these parts of the population. Consequently, cultural diversity, often seen as an advantage for the creative economies, can also be seen as the reflex of economic, social and political inequalities.

In this sense, cities can be seen as a stage for the major social and economic conflicts of contemporary societies, where new types of political actors emerge the "contested cities", as expressed by Sassen (2010), pointing out that frequent unorganized episodes of violence and "delinquency" emerge in contemporary cities (even in the most developed economies) as a form of political protest. As an important consequence for urban sociology, this author suggests, studying contemporary cities is more than studying the urban aspects: it is a very effective way to analyse the major socio-economic transformations of this era, by integrating aspects related to the new information technologies, the relations between transnational and translocal dynamics and different types of sociocultural diversity. Another analysis of the contradictions and conflicts in contemporary cities, more oriented to the processes of cultural production, is proposed by Citroni (2016), highlighting the processes of political mobilization within creative communities.

In fact, much of the social processes that can be observed at the city level today are not strictly urban phenomena, but global structural socio-economic transformations (including economic processes, labour relations, migration flows, social conditions, industrial, commercial and financial globalization or technological innovation), which have deep implications on urban dynamics. While the national sphere seems to lose importance in the context of contemporary globalized economies and societies, with increasing economic and political integration at supranational levels, the local sphere of the cities seems, on the contrary, to acquire a new and more significant role in economic, social, institutional and political terms.

In a context of generalized deregulation, flexibilization and informalization of labour relations - with the consequent loss of importance of traditional forms of political organization and representation, like the unionized workers - the public space of many cities emerges today as the terrain for new forms of social mobilization and protest. Squares in different countries become notorious at 
international level as spaces for political protests: Syntagma (Athens, Greece), Tahrir (Cairo, Egypt), Taksim (Istanbul, Turkey) or Tiannamen (Beijing, China) are just some recent examples. In the same way, slogans globally used in political protests, like "Take the Streets" or "Occupy" clearly claim the request for the public space as a terrain for political conflict. An analysis of the growing importance of cities and public spaces as the stages for political mobilization and confrontation in contemporary societies is proposed by Harvey (2012).

These new forms of mobilization, politization and confrontation in public urban spaces seem to be related to very broad structural societal transformations, including those aspects that are clearly out of the strict scope or urban policies. Nevertheless, the particular implications of agglomeration of creative activities in urban centres, the rents generated by their uniqueness and their utilization in branding strategies and the gentrification processes arising from the commercial dynamics and unequal appropriation of benefits (which were the result of a collective action based on common resources) reinforce the importance of public policies at the city level in order to avoid the social and spatial imbalances resulting from these processes.

\subsection{Culture and the City of Commons}

This approach to the creative externalities and spillovers clearly relates to the concept of "Common Pool Resources". As Scott (2016) suggests, competitive advantages of cities largely rely on freely available public assets and cultural resources, external to markets and not controlled by private ownership or policy and managerial institutions. In fact, cities can be seen as factories for the production of the "Commons" (Harvey, 2012). Nevertheless, despite its importance, mainstream economic theories do not address the question of the Commons sufficiently, generally defining it as a "market failure", out of the scope of the current theorizations on market dynamics or policy regulation.

According to the mainstream approaches to economic systems, firms and households, whose activities are regulated by markets and rely on private property, are the basic unit for decision-making and economic behaviour. Collective action, on the other hand, is ensured by governance institutions, legally legitimized for the social and political regulation of urban areas. In this context, all the communal aspects of urban life, related to the dynamics of a local community to generate the externalities that promote the identity, quality of life and attractiveness of an urban area, are almost completely excluded from the analysis of economic or urban science.

An exception to this lack of attention within contemporary economic science is the work of Elinor Ostrom (2008a; 2008b), who defines the "Common Pool Resources" as including natural and human constructed resources for which it is difficult (although not impossible) to limit access and to define recognized users while excluding others. Often, these are "open-access resources", with free use, which are likely to be overused and potentially destroyed. Being available under 
diverse and evolving property regimes (private, state, communal or open access), these common resources are normally indivisible (with boundaries difficult to delineate), implying subtractability (rivalry among potential users) and nonexcludability. This implies that the use of a common resource can reduce the amount available for other users, but the exclusion of (additional) users is very difficult or even impossible.

General problems related to the Common Pool Resources are the "free ride" (related to degradation or exclusion due to overuse by some users), investment incentive (lack of incentives for preservation), appropriation (which group of users has rights over a given resource). In particular for this case, the appropriation problem applies to the rents generated by cultural and creative activities reinforcing the uniqueness of an urban area: while used in "placebranding" strategies, these rent tend to be appropriate by real estate agents of housing and land owners, after being the result of the creative work of individual agents that do not benefit from it (at least in similar or equal conditions).

Considering the characteristics of these types of resources and the difficulties to measure their value, regulate their usage, share their benefits or even to model their dynamic exploitation, Dietz, Ostrom and Stern (2008) emphasize the importance of implementing, at the local level, governance systems based on adaptive resource management and participatory processes, pointing out some key characteristics (wide participation, community knowledge-based, continual monitoring, flexible policy design and frequent review of management practices) and principles (specificity - actions adapted to different situations, circumstances and contingencies; and precautionarity - diversification of options, conservation of resources and avoidance of waste; subsidiarity - empowerment of individuals and communities for decision making at local level) for its implementation. Although this type of analysis emerged with a strong focus on the usage and management of natural resources, the growing economic importance of information, knowledge and interaction in contemporary cities justifies the application of these theoretical conceptualizations in urban contexts.

\section{CONCLUSION: QUESTIONS FOR THE SCIENCE OF THE CITY}

This paper aimed at combining different concepts and theoretical contributions related to cultural production and urban dynamics in order to show how the generation of creative externalities in an urban context is mostly a collective process, developed through the interactions arising within a community and creating or reinforcing agglomeration effects, through the attractiveness resulting from the uniqueness, authenticity and creative spillovers developed in a place. On the contrary, the appropriation of the benefits arising from these externalities is mostly a private process, often benefiting other individuals and entities (the "upperground") than those who contributed for the development of a creative atmosphere (the "underground"). 
This process can be analysed through the lens of the "Common Pool Resources" approach, emphasizing the communal character of the production of creative externalities, the "appropriation problems" related to the characteristics of these resources (subtractability, nonexcludability, "free ride") and the role that participatory processes of urban management and monitoring can have in order to ensure a more egalitarian process for sharing benefits, to promote social cohesion and, in a final instance, also to keep the uniqueness and authenticity of the creative environment, avoiding the processes of cultural homogenization arising from the commodification of creative activities and the progressive transformation of creative externalities into land rents.

In this context, the main contribution of this analysis is to raise a set of crucial questions, with relevant policy implications, leading to the formulation of a systematic conceptual framework for the analysis of the generation of creative externalities, as a resource commonly produced at community level, and its relation to the social dynamics of appropriation of benefits, in order to promote more inclusive cities, while preserving their creativity and authenticity in the long run. These questions, requiring further empirical research, can be summarized as:

- How to measure and to quantify externalities from creative activities?;

- How to model and to implement fair processes for sharing benefits?;

- What are the implications on city planning, as these are not strictly urban questions?;

- How to integrate urban studies with the analysis of other determinants of social life (like labour conditions or social, institutional and political representation)?.

The answer to these questions requires a more detailed and sophisticated economic analysis of the "Common Pool Resources", combined with sociopolitical analysis of the societal transformations that influence and shape contemporary cities. As stressed by Scott (2007) more attention should be given, at policy level, to internal processes of the system of cognitive and cultural production, as an effort to reinforce social cohesion, effective solidarity within urban communities and democratic participation. Instead, we are witnessing a process of increasing inequalities and injustices in many metropolitan areas, which, at the same time, contribute to a cultural homogenization though the commodification of creative products and the gentrification processes of urban areas.

These problems achieve an even higher relevance if they are framed in a broader analysis of urban development, also taking into consideration the unbalanced relations between the city centres and the peripheral suburbia, the inequalities between high and low skilled workers or the differences in democratic 
participation, institutional representation and active citizenship within urban communities. In this sense, multidisciplinary approaches to the Science of City can have an important role as contributing for more balanced, democratic and creative societies.

\section{REFERENCES}

Avdikos, V., 2015. Processes of creation and commodification of local collective symbolic capital; a tale of gentrification from Athens. City, Culture and Society, 6(4), pp.117-123.

Citroni, S., 2016. The contradictions of creative activism. Situated meanings and everyday practices in a Milan case- study. City, Culture and Society, [online] Available at: <http://www.sciencedirect.com/science/article/pii/S1877916616300273>.

Cohendet, P., Grandadam, D. and Simon, L., 2010. The anatomy of the creative city. Industry and Innovation, [e-journal] 17(1), pp.91-111. http://dx.doi.org/10.1080/13662710903573869.

Cohendet, P., Grandadam, D. and Simon, L., 2011. Rethinking urban creativity: lessons from Barcelona and Montreal. City, Culture and Society, [e-journal] 2(3), pp.151-158. http://dx.doi.org/10.1016/j.ccs.2011.06.001.

Currid-Halkett, E. and Scott, A.E., 2013. The geography of celebrity and glamour: Reflections on economy, culture, and desire in the city. City, Culture $\begin{array}{llllll}\text { and Society, } \quad \text { [e-journal] } & 4(1), & \text { pp.2 } & - & 11 .\end{array}$ http://dx.doi.org/10.1016/j.ccs.2013.01.003.

Davis, M., 2006. A Planet of Slums. New York: Verso.

Dietz, T., Ostrom, E. and Stern, P.C., 2008. The Struggle to Govern the Commons. In: J. Marzluff, E. Shulenberger, W. Endlicher, M. Alberti, G. Bradley, C. Ryan, C. Zum Brunnen and U. Simon, eds. 2008. Urban Ecology An International Perspective on the Interaction Between Humans and Nature. Berlin: Springer. pp.611-622.

Doucet, B., 2014. A Process of Change and a Changing Process: Introduction to the Special Issue on Contemporary Gentrification. Tijdschrift voor Economische en Sociale Geografie, 105(2), pp.125-139.

Harvey, D., 2012. Rebel Cities. New York: Verso.

Florida, R.L., 2002. The rise of the creative class: And how it's transforming work, leisure, community and everyday life. New York: Basic Books.

Van Geenhuizen, M. and Nijkamp, P., 2012. Creative Knowledge Cities: Myths, Visions and Realities. Cheltenham: Edward Elgar Publishing.

Okano, H. and Samson, D., 2010. Cultural urban branding and creative cities: A theoretical framework for promoting creativity in the public spaces. Cities, 27 , pp.S10-S15. 
Ostrom, E., 2008a. The challenge of Common-Pool Resources. Environment, 50(4), pp.8-20.

Ostrom, E., 2008b. Institutions and the Environment. Economic Affairs, 28(3), pp.24-31.

Sassen, S., 2010. The city: Its return as a lens for social theory. City, Culture and Society, 1, pp.3-11.

Scott, A.J., 2007. Capitalism and Urbanization in a New Key? The CognitiveCultural Dimension. Social Forces, [e-journal] 85(4), pp.1465 - 1482. http://dx.doi.org/10.1353/sof.2007.0078.

Scott, A.J., 2008. Resurgent Metropolis: Economy, Society and Urbanization in an Interconnected World. International Journal of Urban and Regional Research, 32(3), pp.548-564.

Scott, A.J., 2016. City and Society: An Inquiry into the Logic of Urban Development and its Meaning for Work and Life in the Twenty-First Century. Academia.edu., [online] Available at: $<$ https://www.academia.edu/12084353/CITY_AND_SOCIETY_An_Inquiry_into_th e_Logic_of_Urban_Development_and_its_Meaning_for_Work_and_Life_in_the_Tw enty-First_Century> [Accessed 15 March 2016].

UNESCO, 2009. Framework for Cultural Statistics. Montreal: UNESCO.

\section{ABOUT THE AUTHOR}

João Romão is a Post-Doc Researcher in tourism and regional science at CEFAGE (Center for Advanced Studies in Management and Economics University of Algarve) and a Guest Researcher at Hokkaido University (Japan), with previous research experiences at the Spatial Economics Department of Vrije Universiteit (Amsterdam, Netherlands) and the Yale School of Forestry and Environment (Yale University, New Haven, USA). He holds a Ph.D. in Tourism (2012, University of Algarve, Portugal), BA in Economics (1991, Lisbon School of Economics, Portugal) and MSc. in Economics and Management of Science and Technology (1995, Lisbon School of Economics). His research interests and experience as a consultant are focused on the relation between territorial resources, innovation, urban planning, tourism dynamics and sustainable regional development. CEFAGE (Center for Advanced Studies in Management and Economics - University of Algarve), jfromao@ualg.pt. 